\title{
Kerogen Swelling in Light Hydrocarbon Gases and Liquids and Validity of Schroeder's Paradox
}

\author{
Zheng Li ${ }^{a, b}$, Jun Yao ${ }^{a}$, and Abbas Firoozabadi ${ }^{b, *}$ \\ ${ }^{a}$ Research Center of Multiphase Flow in Porous Media, China University of Petroleum (East \\ China), Qingdao, Shandong, 266580, China \\ b Department of Chemical and Biomolecular Engineering, Rice University, Houston, Texas, \\ 77005, USA \\ *E-mail: abbas.firoozabadi@rice.edu
}




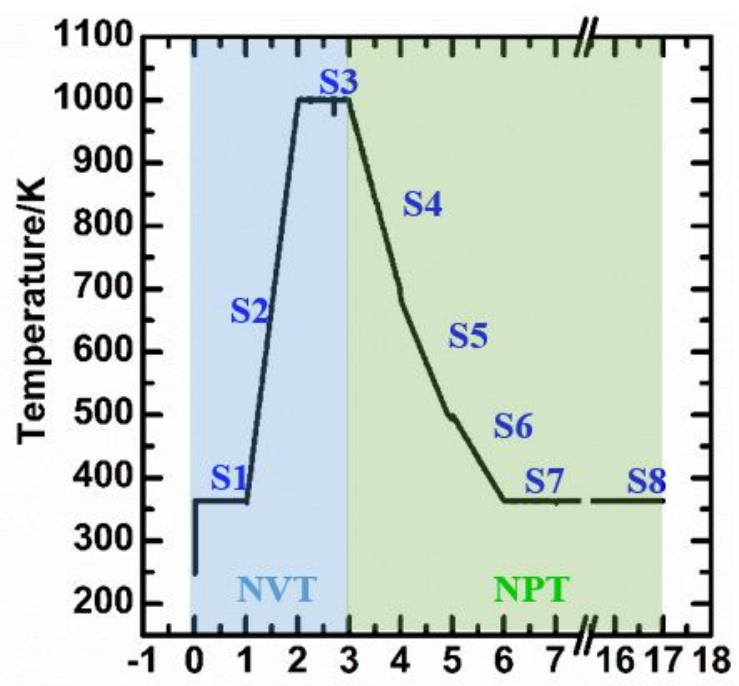

(a)

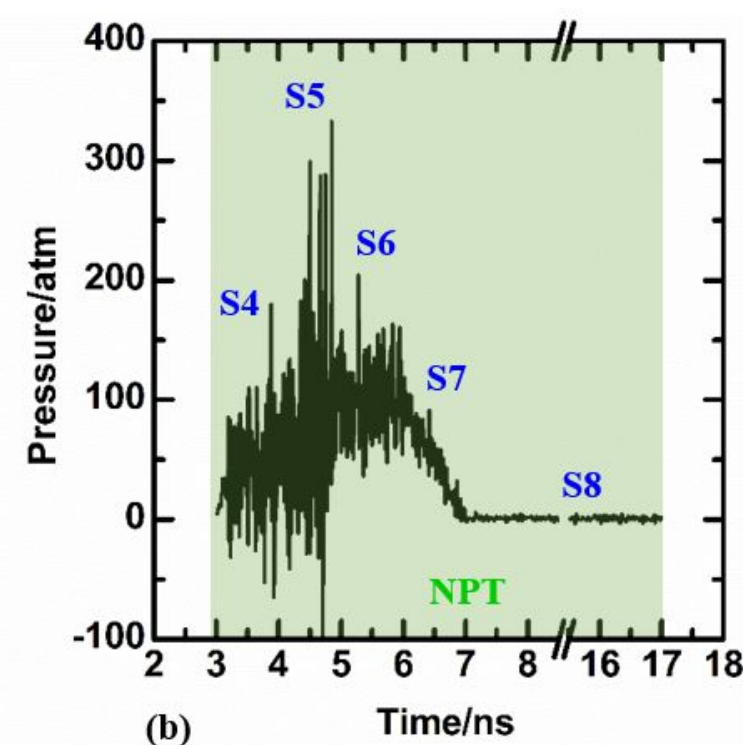

(b)

Figure S1. (a) Temperature vs. time, and (b) pressure vs. time from molecular dynamics relaxation from Stage $1(\mathrm{~S} 1)$ to Stage $8(\mathrm{~S} 8)$.

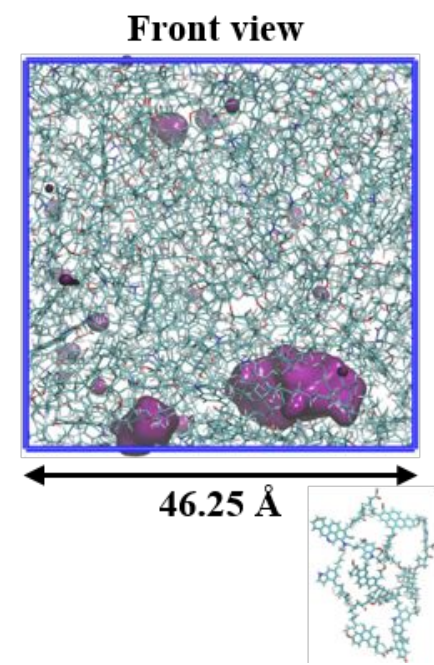

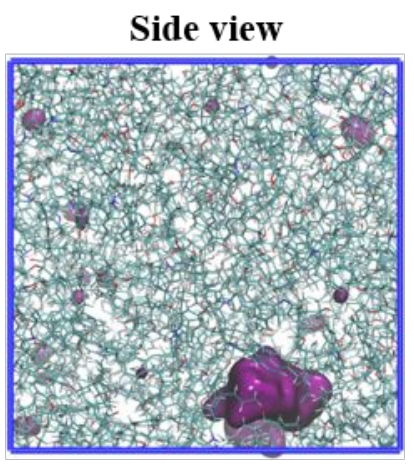

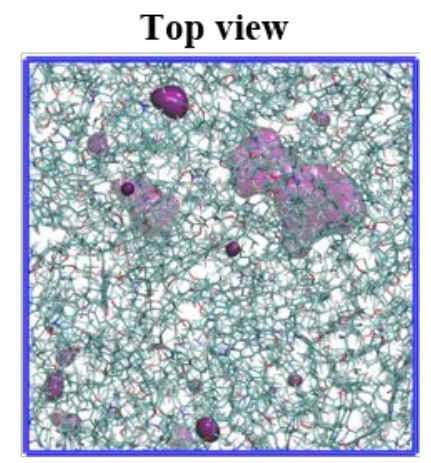

Kerogen macromolecule

Figure S2. Pore surface area of the kerogen matrix at the end of 100-ns NPT simulations:

without dummy particle 
(a)

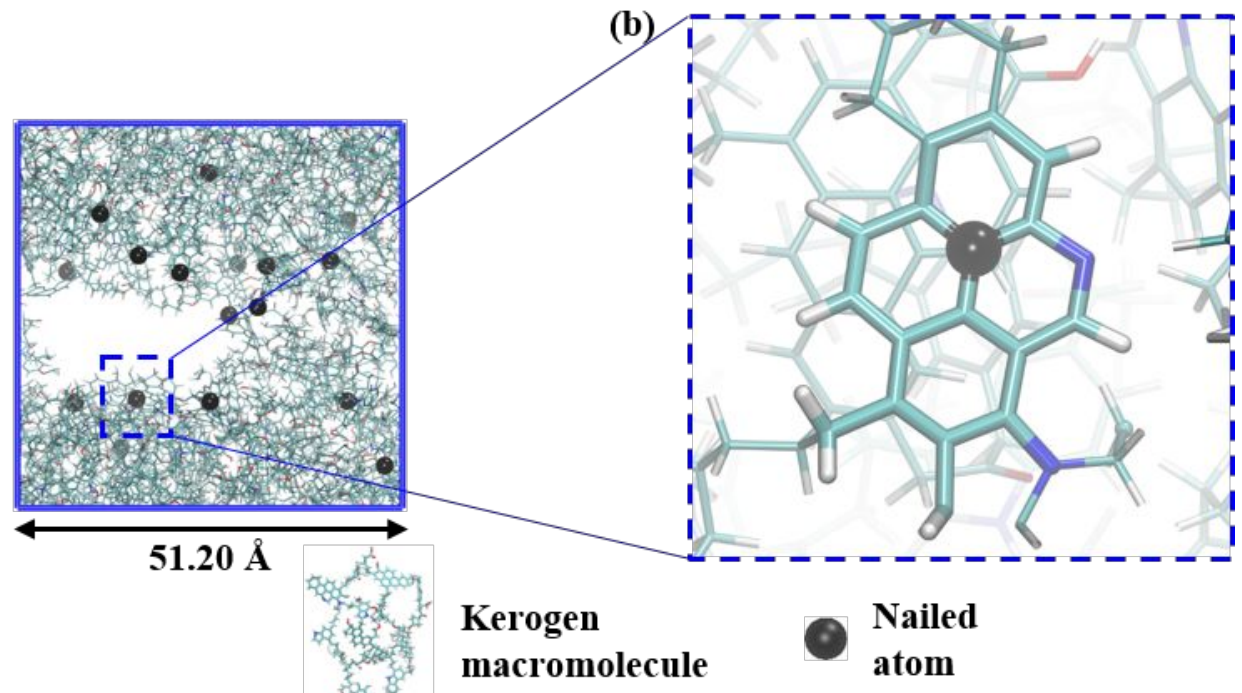

Figure S3. (a) Front view of the simulation box at the start of stage 9 without dummy particle with 17 nailed atoms marked in black. (b) Magnified polyaromatic cluster with one nailed atom marked in black. 


\section{Nailing of selected atoms}

The method of nailing of selecting atoms was proposed by $\mathrm{Wu}$ and Firoozabadi ${ }^{1}$ in construction of flexible kerogen matrix in investigation of gas flow. The suggestion was motivated to prevent the kerogen matrix from being displaced and allow the matrix pores from collapsing under high stress conditions. Very few Nailed atoms are frozen. In our work we follow the idea of using a flexible kerogen matrix to investigate kerogen swelling by hydrocarbon sorption. To prevent the collapse of large pores, selected carbon atoms located at the center of polyaromatic clusters in the periphery of the pores are frozen/nailed (Figure S3). The same method has also been used by Tesson and Firoozabadi ${ }^{2}$. The method is essentially to freeze the atoms by excluding them from the time integration to keep the kerogen structural flexibility. At the same time, large pores/macroscopic position of the kerogen matrix are maintained.

The number of nailed atoms may affect the flexibility of the kerogen matrix ${ }^{2}$. If all the atoms are nailed which is common by various authors in the past, the kerogen matrix will be rigid and may not swell. When the number of nailed atoms is limited $(0.17 \%$ in our work, $0.16 \%$ in $\mathrm{Wu}$ and Firoozabadi ${ }^{1}$, and $0.17 \%$ in Tesson and Firoozabadi ${ }^{2}$ ) and the positions of nailed atoms are well-selected, microstructural flexibility of the kerogen matrix will be maintained. Porosity comparison in Table 2 shows the effectiveness of nailed atoms to prevent the pores from collapsing; the swelling ratios in Figure 5 illustrate that the matrix can deform with nailed atoms.

One may argue that the nailed atoms restrain kerogen swelling and macroscopic swelling is reduced with respect to a truly free swelling. But the effects are negligible when the number of nailed atoms is very small and the kerogen swelling is not large as Figures S8 to S10 suggest. The effect of very limited nailing is expected to be the same for solvent gas and liquid states. Moreover, the limited nailed atoms will not affect the swelling trend in relation to validity of Schroeder's paradox. 


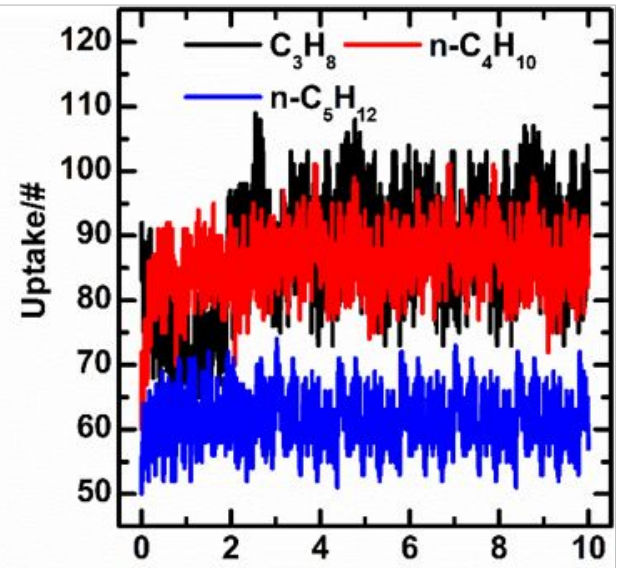

(a) Time/ns

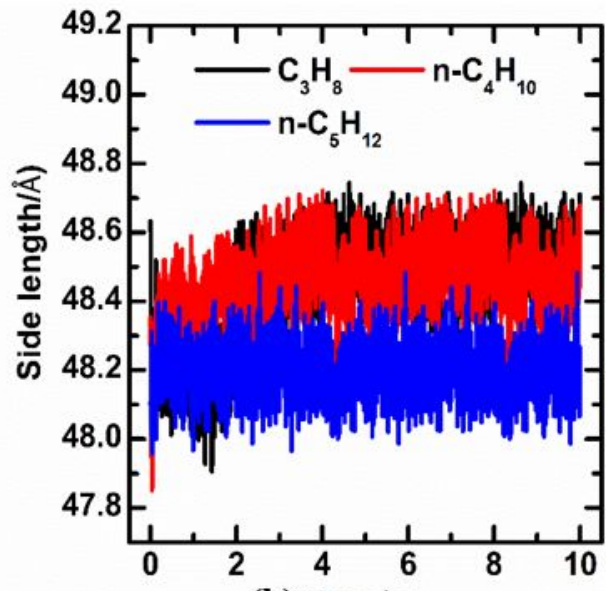

(b) Time/ns

Figure S4. (a) Uptake in number of hydrocarbon molecules, and (b) box side length vs. simulation time at $4.0 \mathrm{~atm}: T=363.15 \mathrm{~K}$ 
Table S1. Structural characteristics of the kerogen matrix with 17 nailed atoms at different

$$
\text { pressures }(T=363.15 \mathrm{~K})
$$

\begin{tabular}{|c|c|c|c|c|c|}
\hline \multirow[b]{2}{*}{$p(\mathrm{~atm})$} & \multicolumn{5}{|c|}{ Structural characteristics } \\
\hline & $\begin{array}{c}\text { Box side } \\
\text { length }(\AA)\end{array}$ & $\begin{array}{l}\text { Bulk density } \\
\qquad\left(\mathrm{g} / \mathrm{cm}^{3}\right)\end{array}$ & $\begin{array}{l}\text { Skeletal } \\
\text { density } \\
\left(\mathrm{g} / \mathrm{cm}^{3}\right)\end{array}$ & $\begin{array}{l}\text { Porosity } \\
\text { (\%) }\end{array}$ & $\begin{array}{c}\text { Pore } \\
\text { surface } \\
\text { area } \\
\left(\mathrm{m}^{2} / \mathrm{g}\right)\end{array}$ \\
\hline 1 & 48.16 & 0.98 & 1.13 & 13.04 & 381.90 \\
\hline 10 & 48.15 & 0.98 & 1.13 & 12.83 & 360.56 \\
\hline 20 & 48.12 & 0.99 & 1.13 & 12.49 & 342.45 \\
\hline 40 & 48.01 & 0.99 & 1.13 & 12.01 & 324.03 \\
\hline 60 & 47.90 & 1.00 & 1.13 & 11.50 & 305.36 \\
\hline 40 & 48.00 & 0.99 & 1.13 & 12.00 & 322.33 \\
\hline 20 & 48.11 & 0.99 & 1.13 & 12.45 & 340.32 \\
\hline 10 & 48.14 & 0.98 & 1.13 & 12.81 & 358.73 \\
\hline 1 & 48.16 & 0.98 & 1.13 & 12.99 & 380.26 \\
\hline
\end{tabular}


Table S2. Saturation pressures of $\mathrm{C}_{3} \mathrm{H}_{8}, \mathrm{n}-\mathrm{C}_{4} \mathrm{H}_{10}$ and $\mathrm{n}-\mathrm{C}_{5} \mathrm{H}_{12}{ }^{3}$

\begin{tabular}{ccc}
\hline$T / \mathrm{K}$ & Hydrocarbon & Saturation pressure/atm \\
\hline 363.15 & $\mathrm{C}_{3} \mathrm{H}_{8}$ & 37.17 \\
\cline { 2 - 3 } & $\mathrm{n}-\mathrm{C}_{4} \mathrm{H}_{10}$ & 12.33 \\
\hline & $\mathrm{n}-\mathrm{C}_{5} \mathrm{H}_{12}$ & 4.64 \\
\hline
\end{tabular}



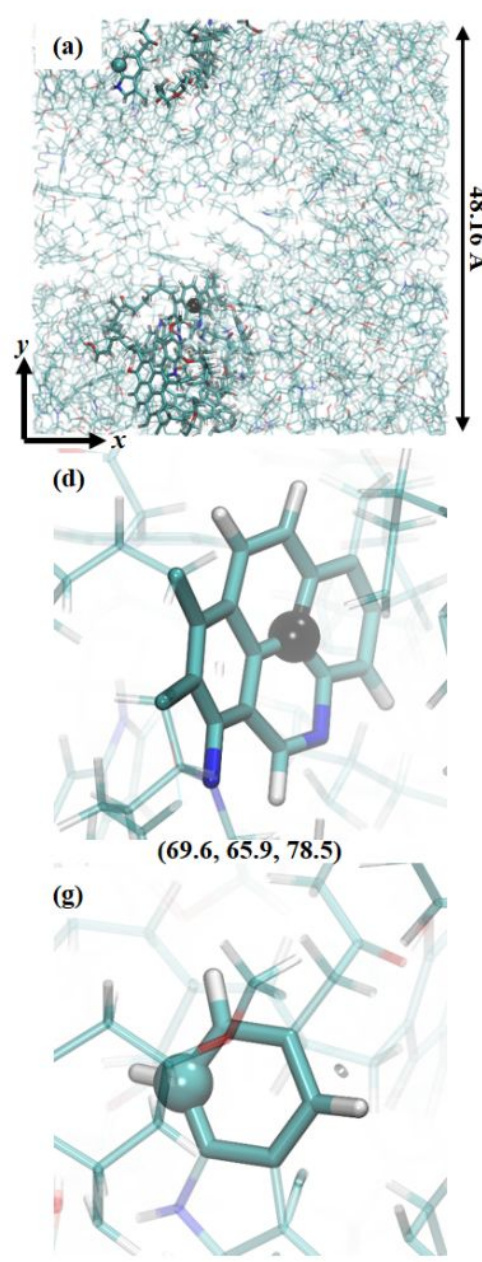

$(60.9,93.8,90.2)$
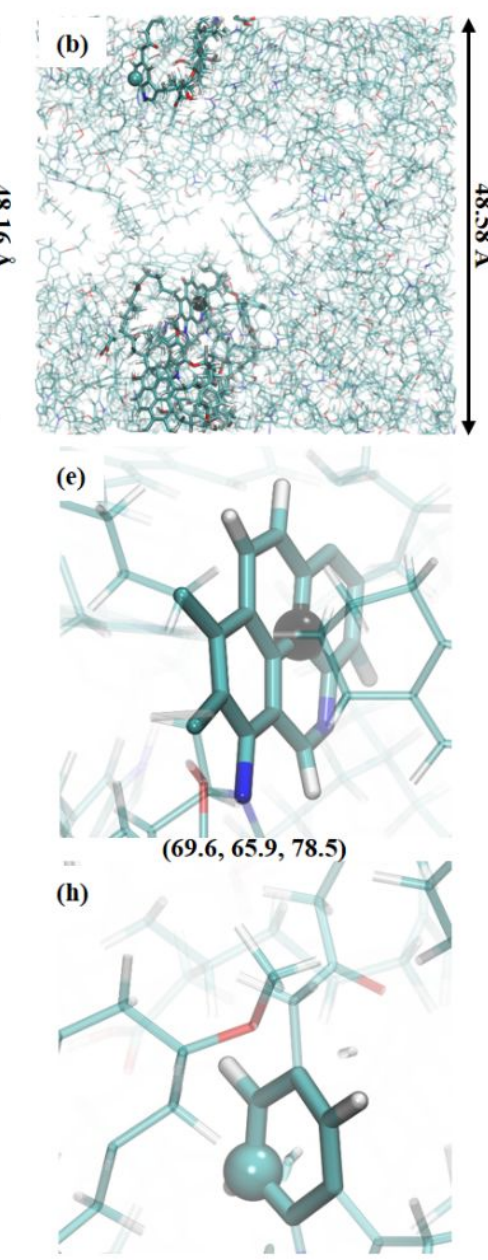

$(62.2,92.0,89.4)$

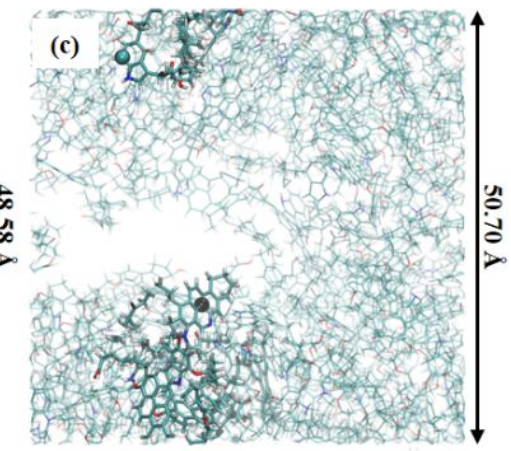

(f)
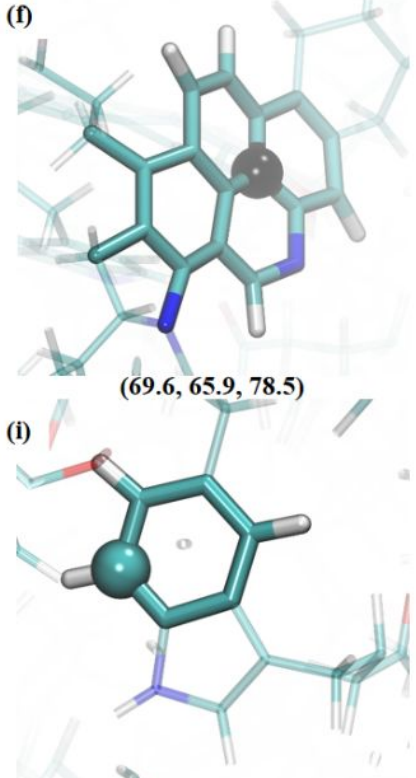

$(60.4,94.6,92.9)$

Figure S5. Front views of kerogen matrix (a) before, and after sorption at (b) $P=37.0 \mathrm{~atm}$, and (c) 38.0. The nailed carbon atom (black), and one free carbon atom (cyan) of the same kerogen molecule $\left(\mathrm{C}_{3} \mathrm{H}_{8}\right.$ molecules are not shown for clarity). Magnified views and coordinates of the nailed carbon atom and the free carbon atom and corresponding hexatomic rings from (a) to (c) are shown in panels (d) to (f), and (g) to (i), respectively: $\mathrm{C}_{3} \mathrm{H}_{8}, T=$ $363.15 \mathrm{~K}$ 


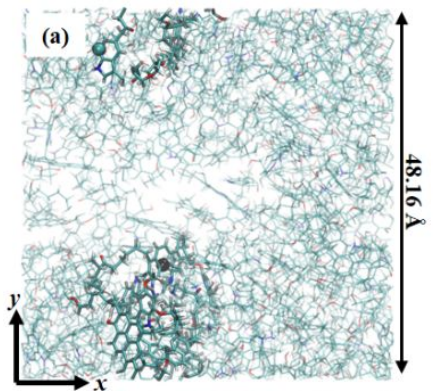

(d)

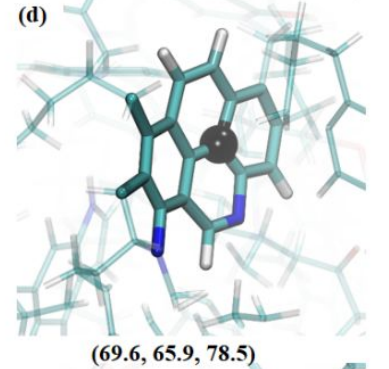

(g)

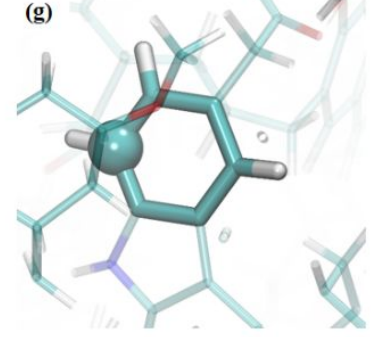

$(60.9,93.8,90.2)$
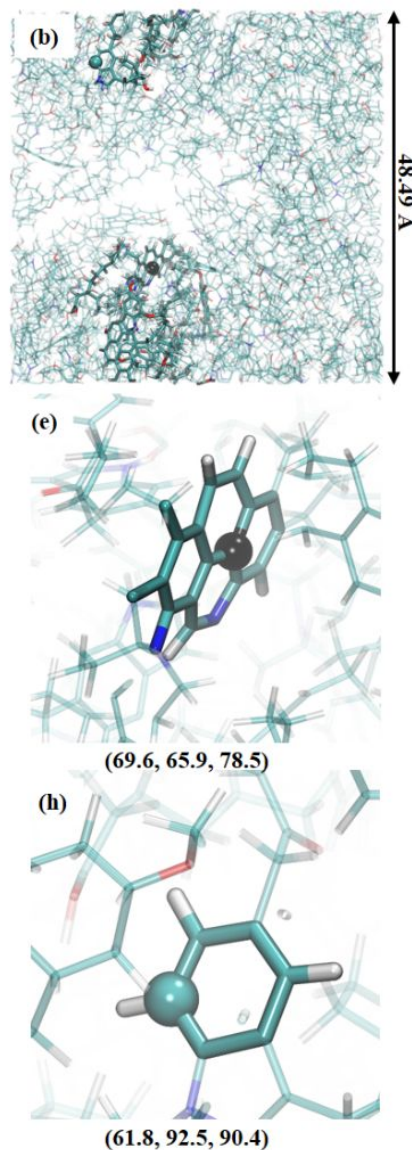
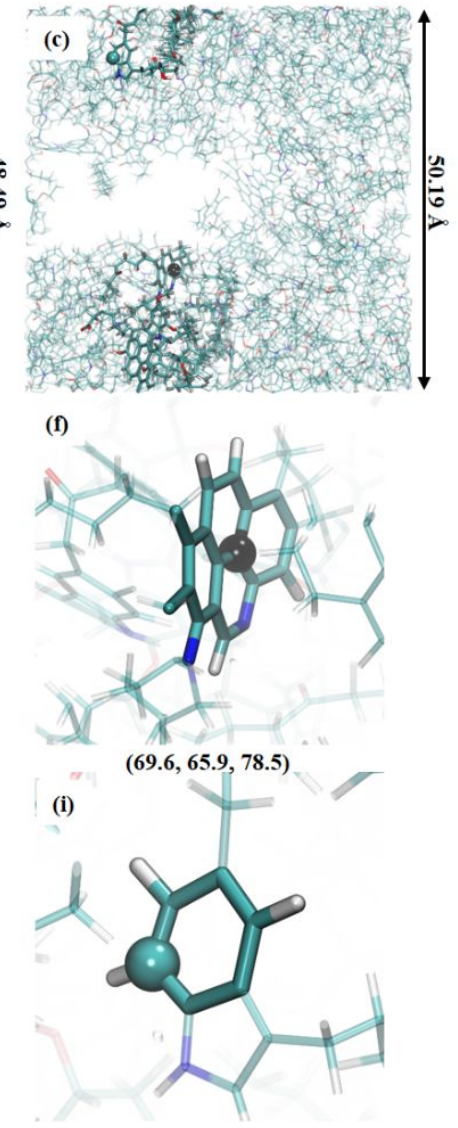

$(61.3,93.3,91.8)$

Figure S6. Front views of kerogen matrix (a) before and after sorption at (b) 12.0 atm and (c) $13.0 \mathrm{~atm}$. The nailed carbon atom (black), and one free carbon atom (cyan) of the same kerogen molecule ( $n-\mathrm{C}_{4} \mathrm{H}_{10}$ molecules are not shown for clarity). Magnified views and coordinates of the nailed carbon atom and the free carbon atoms and corresponding hexatomic rings from (a) to (c) are shown in panels (d) to (f), and (g) to (i), respectively: n$\mathrm{C}_{4} \mathrm{H}_{10}, T=363.15 \mathrm{~K}$ 

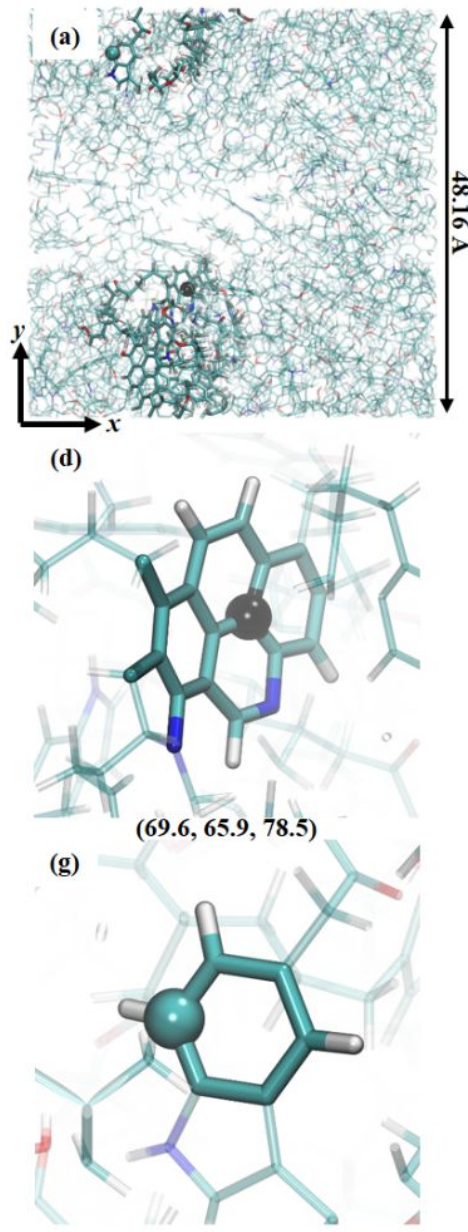

$(60.9,93.8,90.2)$
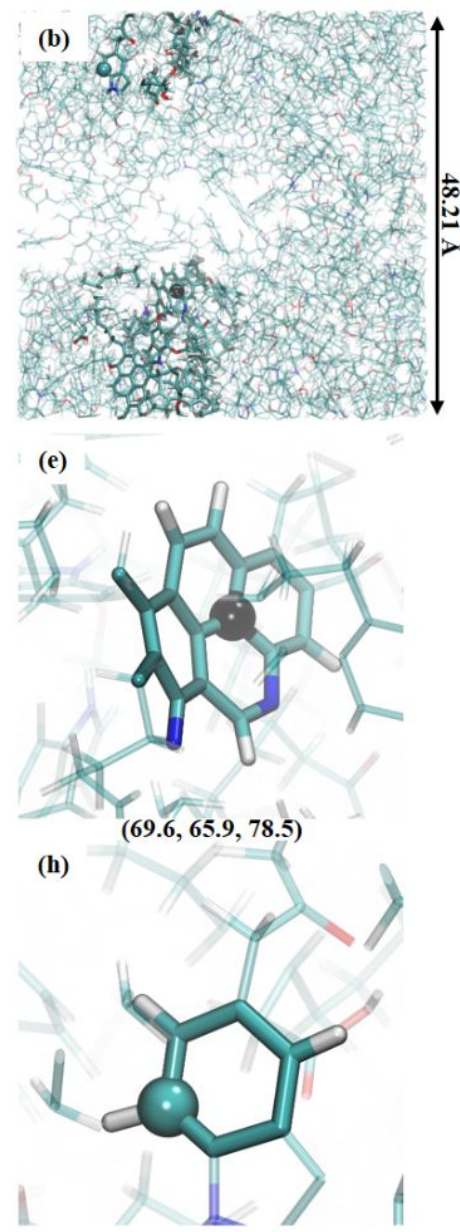

(61.1, 92.1, 90.6)

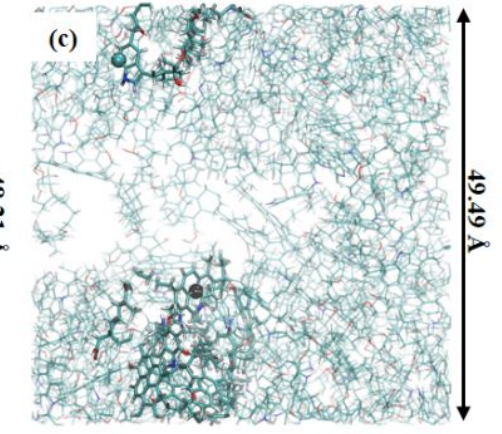

(f)

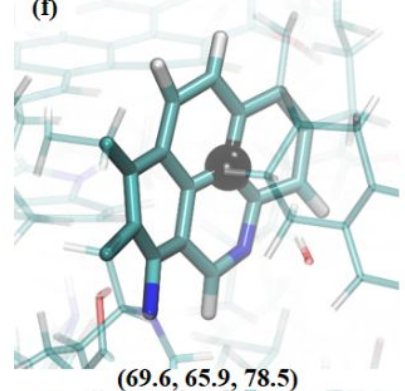

(i)

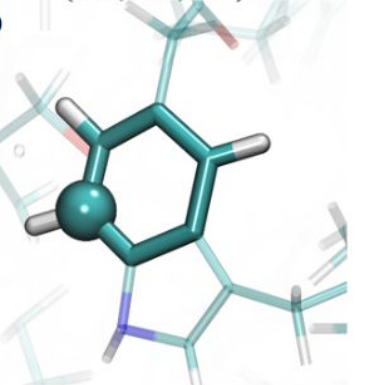

$60.6,93.2,91.5$ )

Figure S7. Front views of kerogen matrix (a) before and after sorption at (b) 4.0 atm and (c) $5.0 \mathrm{~atm}$. The nailed carbon atom (black), and one free carbon atom (cyan) of the same kerogen molecule ( $\mathrm{n}-\mathrm{C}_{5} \mathrm{H}_{12}$ molecules are not shown for clarity). Magnified views and coordinates of the nailed carbon atom and the free carbon atoms and corresponding hexatomic rings from (a) to (c) are shown in panels (d) to (f), and (g) to (i), respectively: n$\mathrm{C}_{5} \mathrm{H}_{12}, T=363.15 \mathrm{~K}$ 
(a)

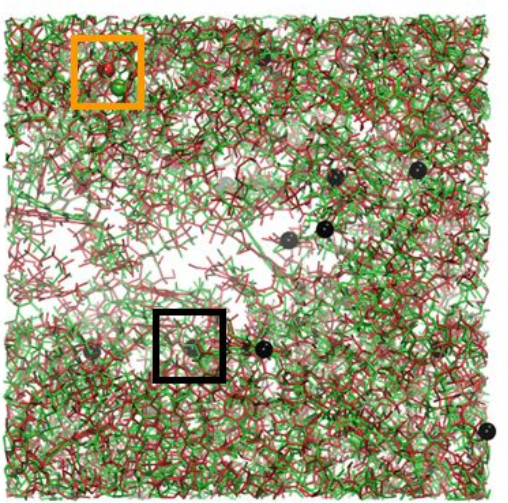

(c)

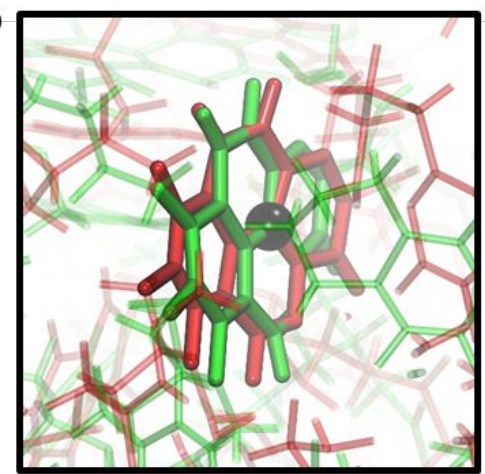

(e)

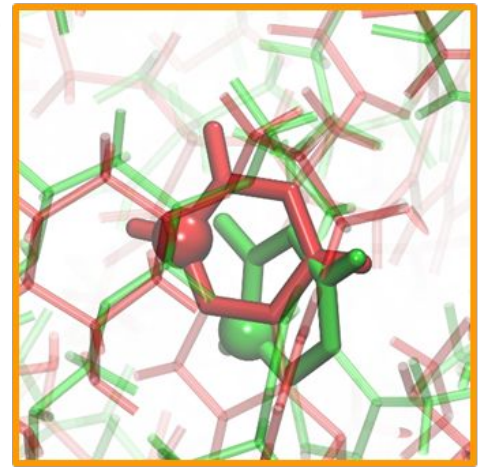

(b)

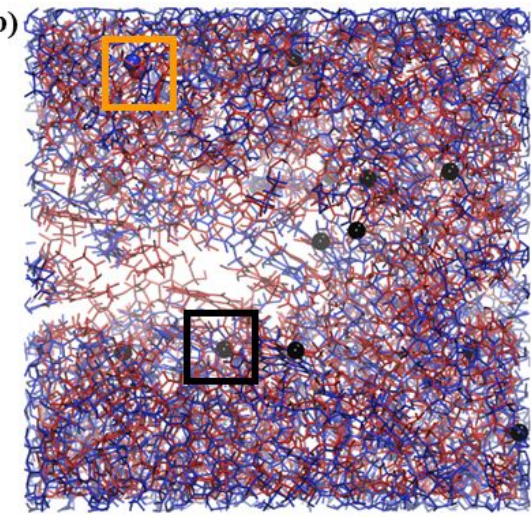

(d)

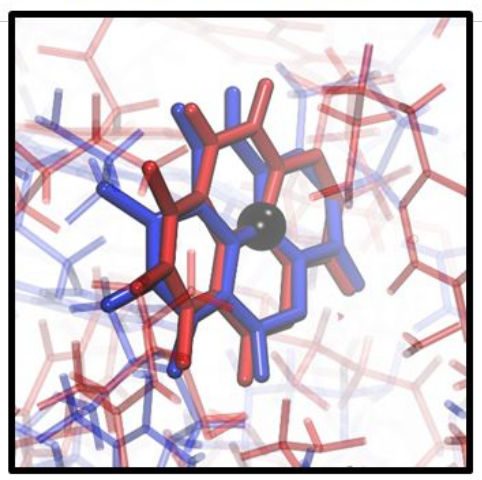

(f)

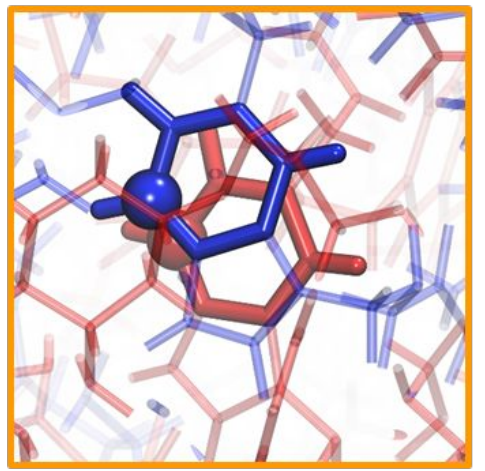

Kerogen matrix before adsorption, side length: $48.16 \AA$

Kerogen matrix after gas adsorption, side length: $48.58 \AA, P: 37.0 \mathrm{~atm}$

Kerogen matrix after liquid adsorption, side length: $50.70 \AA, P: 38.0 \mathrm{~atm}$

Nailed carbon atom

Tracked free carbon atom

Figure S8. Front view of kerogen matrix before (red sticks) and after sorption from gas state (green sticks) and from liquid state (blue sticks). (a) and (b) full views, (c) and (d) magnified views of polyaromatic clusters around the nailed carbon atom before and after sorption, (e) and (f) magnified views of a tracked free carbon atom and the hexatomic ring before and after sorption: $\mathrm{C}_{3} \mathrm{H}_{8}, T=363.15 \mathrm{~K}$ 
(a)

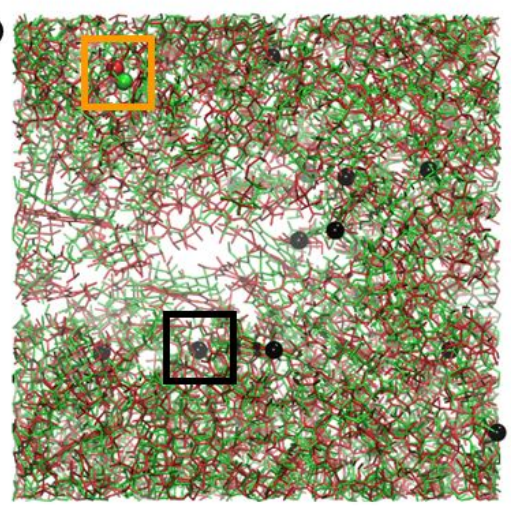

(c)

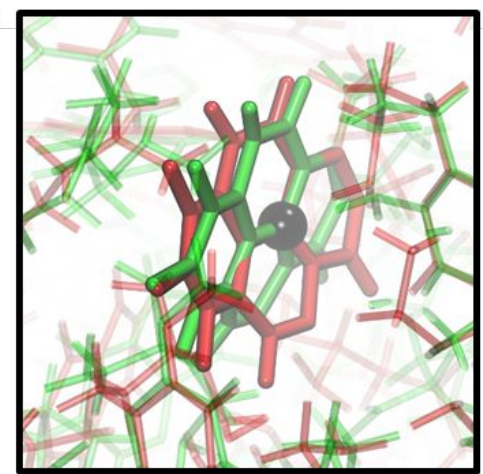

(e)

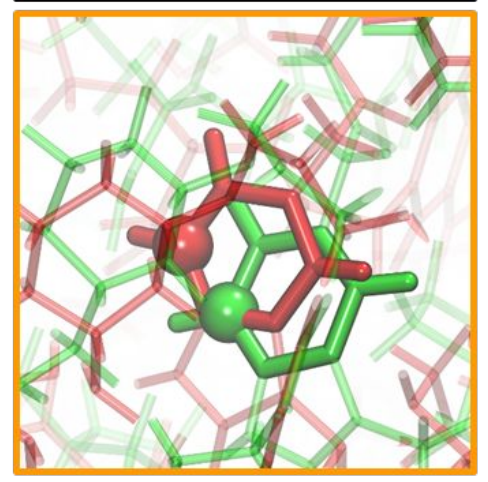

(b)

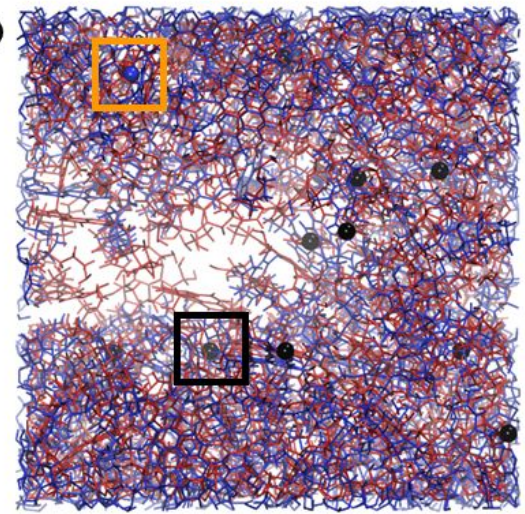

(d)

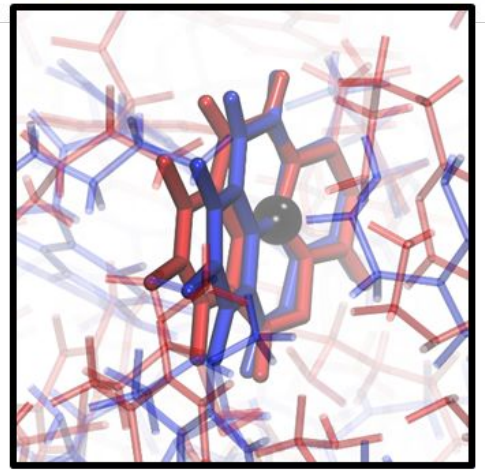

(f)

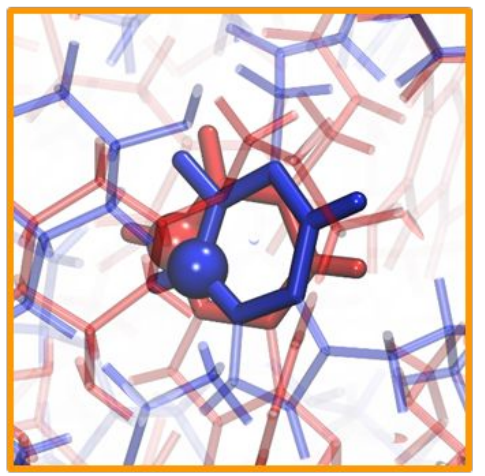

Kerogen matrix before adsorption, side length: $48.16 \AA$

Kerogen matrix after gas adsorption, side length: $48.49 \AA, P: 12.0 \mathrm{~atm}$

Kerogen matrix after liquid adsorption, side length: $50.19 \AA, P: 13.0 \mathrm{~atm}$

Nailed carbon atom

$\odot$ Tracked free carbon atom

Figure S9. Front view of kerogen matrix before (red sticks) and after sorption from gas state (green sticks) and from liquid state (blue sticks). (a) and (b) full views, (c) and (d) magnified views of polyaromatic clusters around the nailed carbon atom before and after sorption, (e) and (f) magnified views of a tracked free carbon atom and the hexatomic ring before and after sorption: $\mathrm{n}-\mathrm{C}_{4} \mathrm{H}_{10}, T=363.15 \mathrm{~K}$ 
(a)

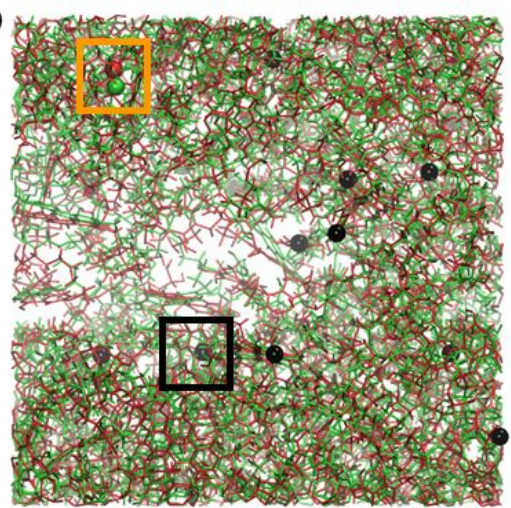

(c)

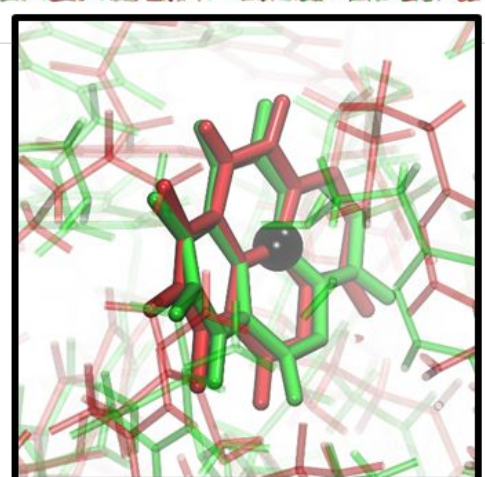

(e)

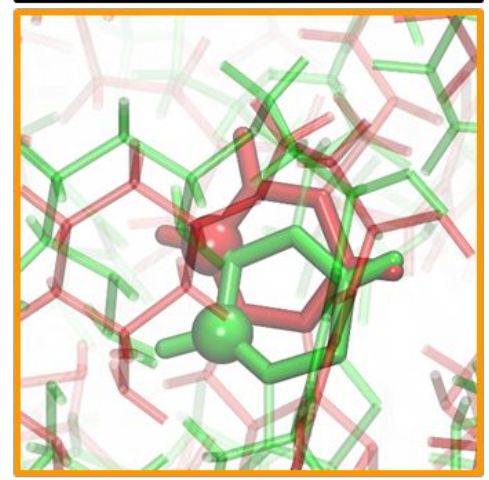

(b)

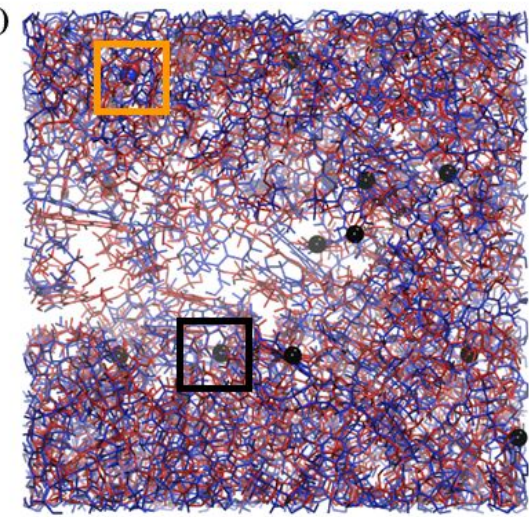

(d)

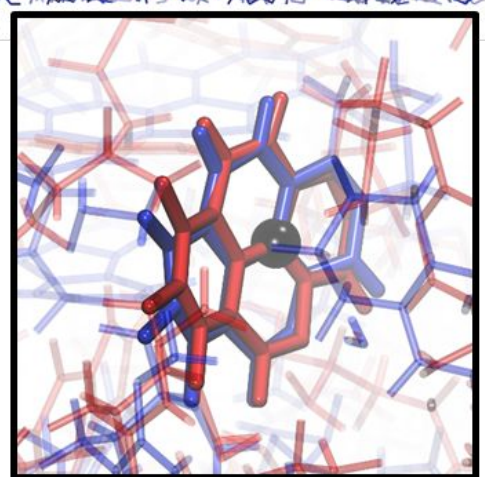

(f)

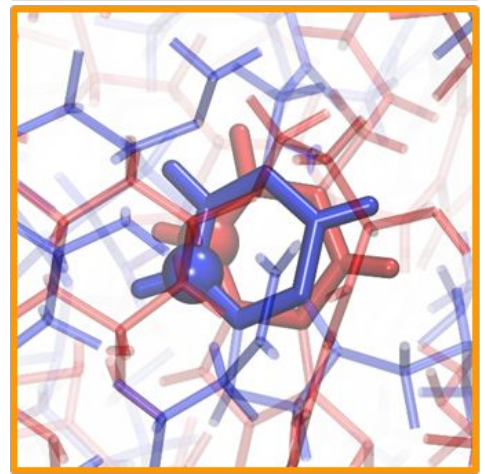

Kerogen matrix before adsorption, side length: $48.16 \AA$

Kerogen matrix after gas adsorption, side length: $48.21 \AA, P: 4.0 \mathrm{~atm}$

Kerogen matrix after liquid adsorption, side length: $49.49 \AA, P: 5.0 \mathrm{~atm}$

Nailed carbon atom

$\odot>$ Tracked free carbon atom

Figure S10. Front view of kerogen matrix before (red sticks) and after sorption from gas state (green sticks) and from liquid state (blue sticks). (a) and (b) full views, (c) and (d) magnified views of polyaromatic clusters around the nailed carbon atom before and after sorption, (e) and (f) magnified views of a tracked free carbon atom and the hexatomic ring before and after sorption: $\mathrm{n}-\mathrm{C}_{5} \mathrm{H}_{12}, T=363.15 \mathrm{~K}$ 
(a) $4.0 \mathrm{~atm}$
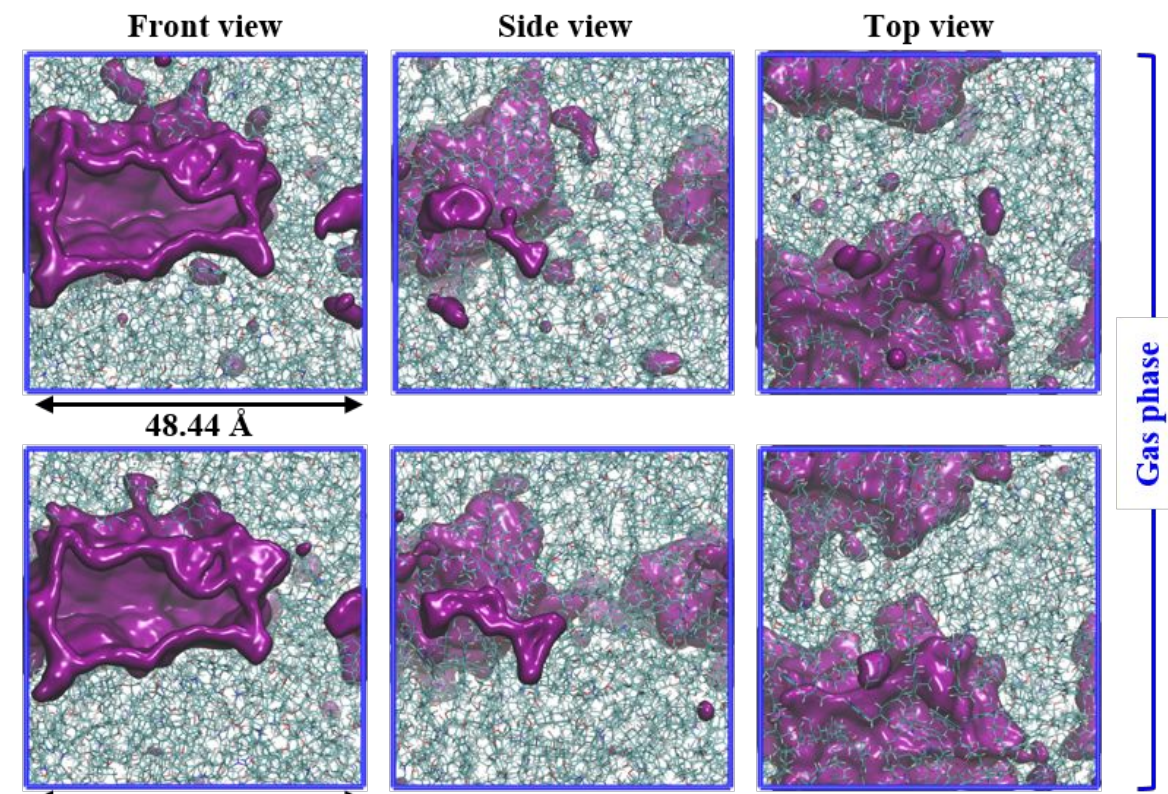

(b) $12.0 \mathrm{~atm}$
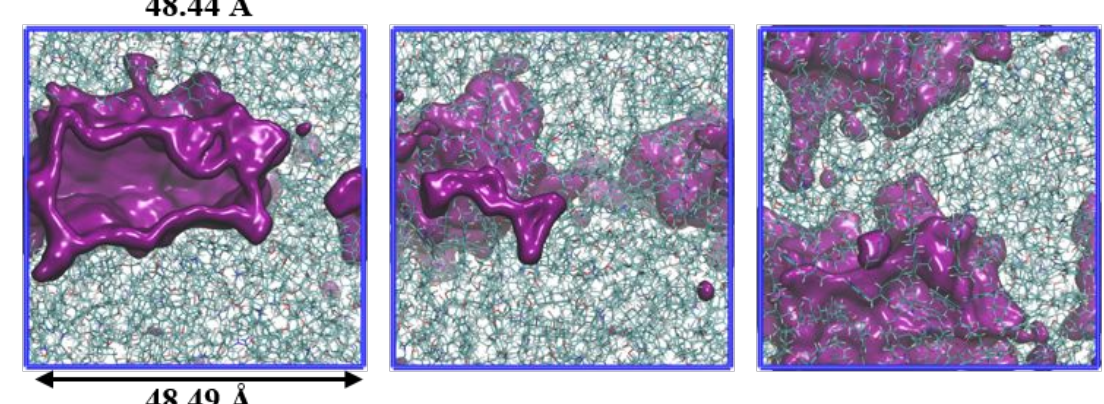

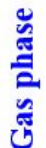

(c) $13.0 \mathrm{~atm}$
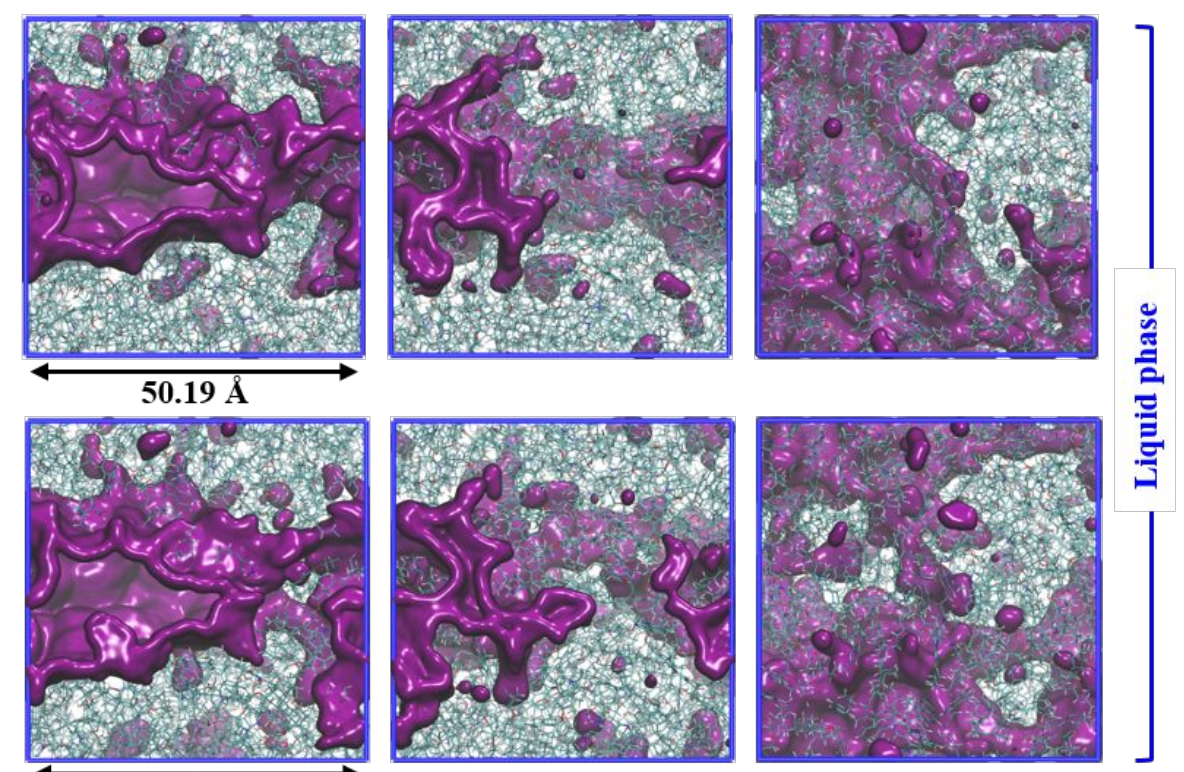

(d) $30.0 \mathrm{~atm}$
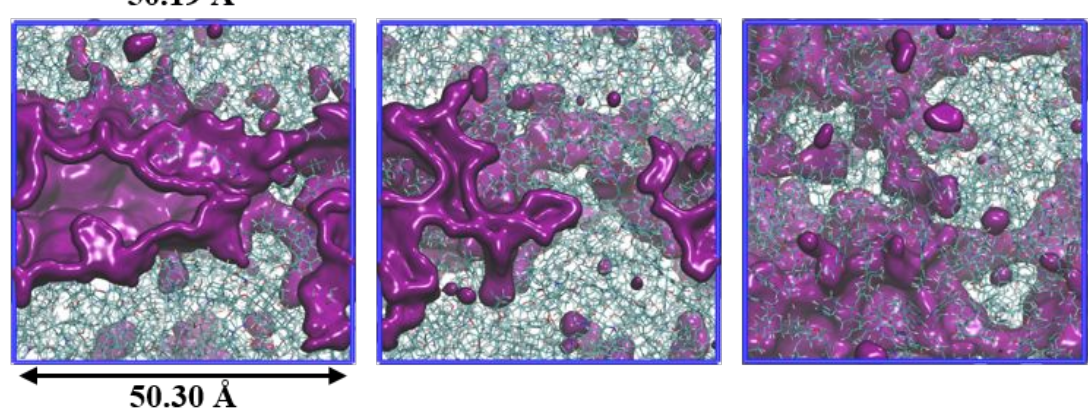

Figure S11. Front, side and top view of pore surface area of the flexible kerogen matrix from n- $\mathrm{C}_{4} \mathrm{H}_{10}$ sorption at different pressures: $T=363.15 \mathrm{~K}$. 
(a) $2.0 \mathrm{~atm}$
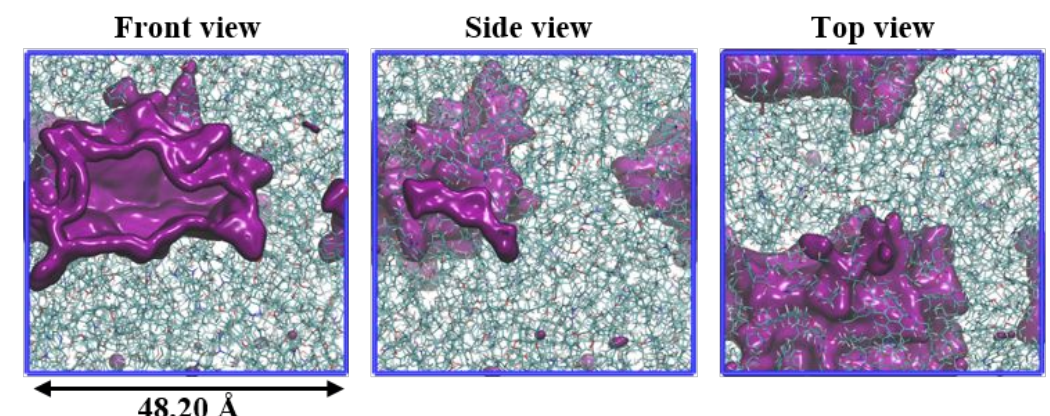

(b) $4.0 \mathrm{~atm}$
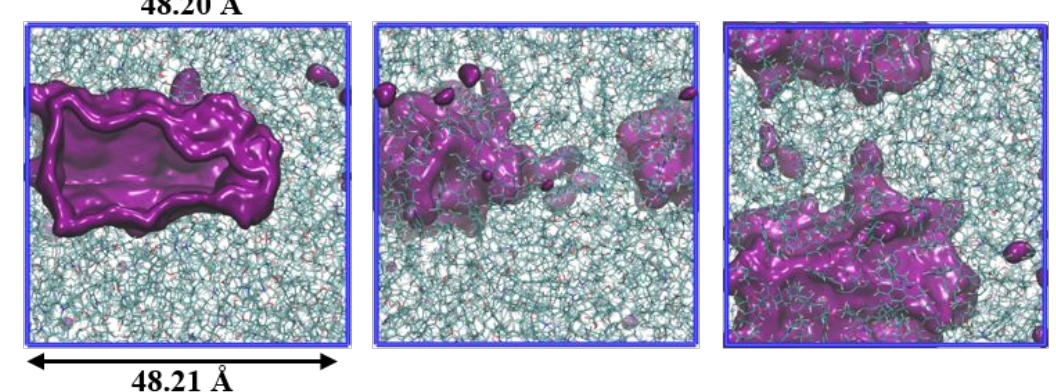

華

(c) $5.0 \mathrm{~atm}$
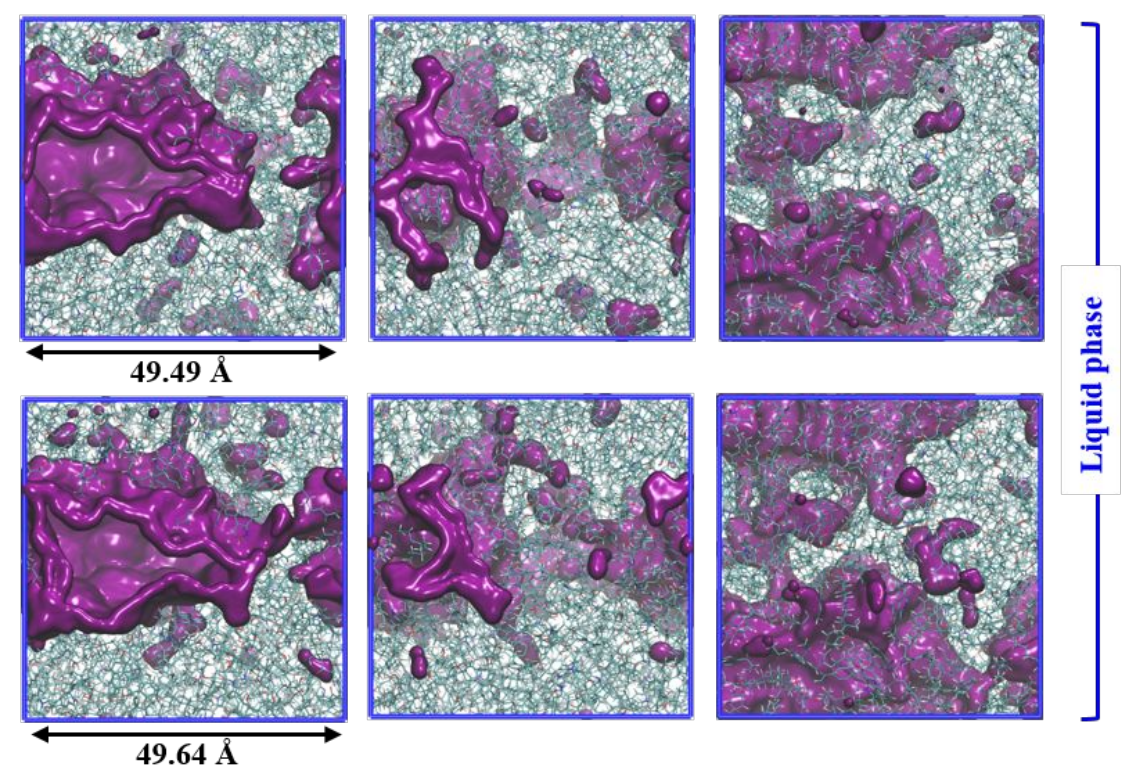

Figure S12. Front, side and top view of pore surface area of the flexible kerogen matrix from n- $\mathrm{C}_{5} \mathrm{H}_{12}$ sorption at different pressures: $T=363.15 \mathrm{~K}$. 


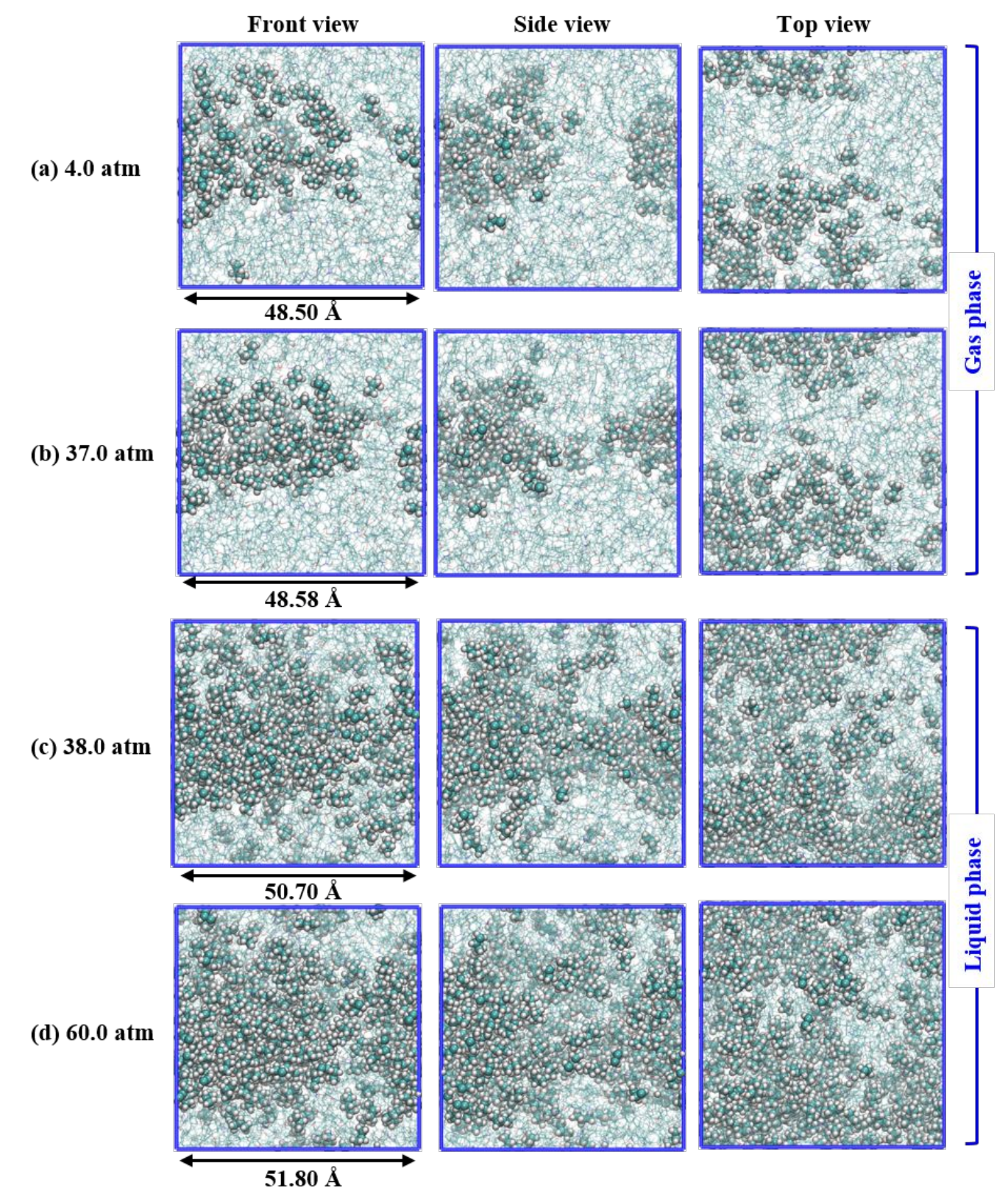

Figure S13. Front, side and top view of the flexible kerogen matrix with $\mathrm{C}_{3} \mathrm{H}_{8}$ sorption at different pressures: $T=363.15 \mathrm{~K}$. 


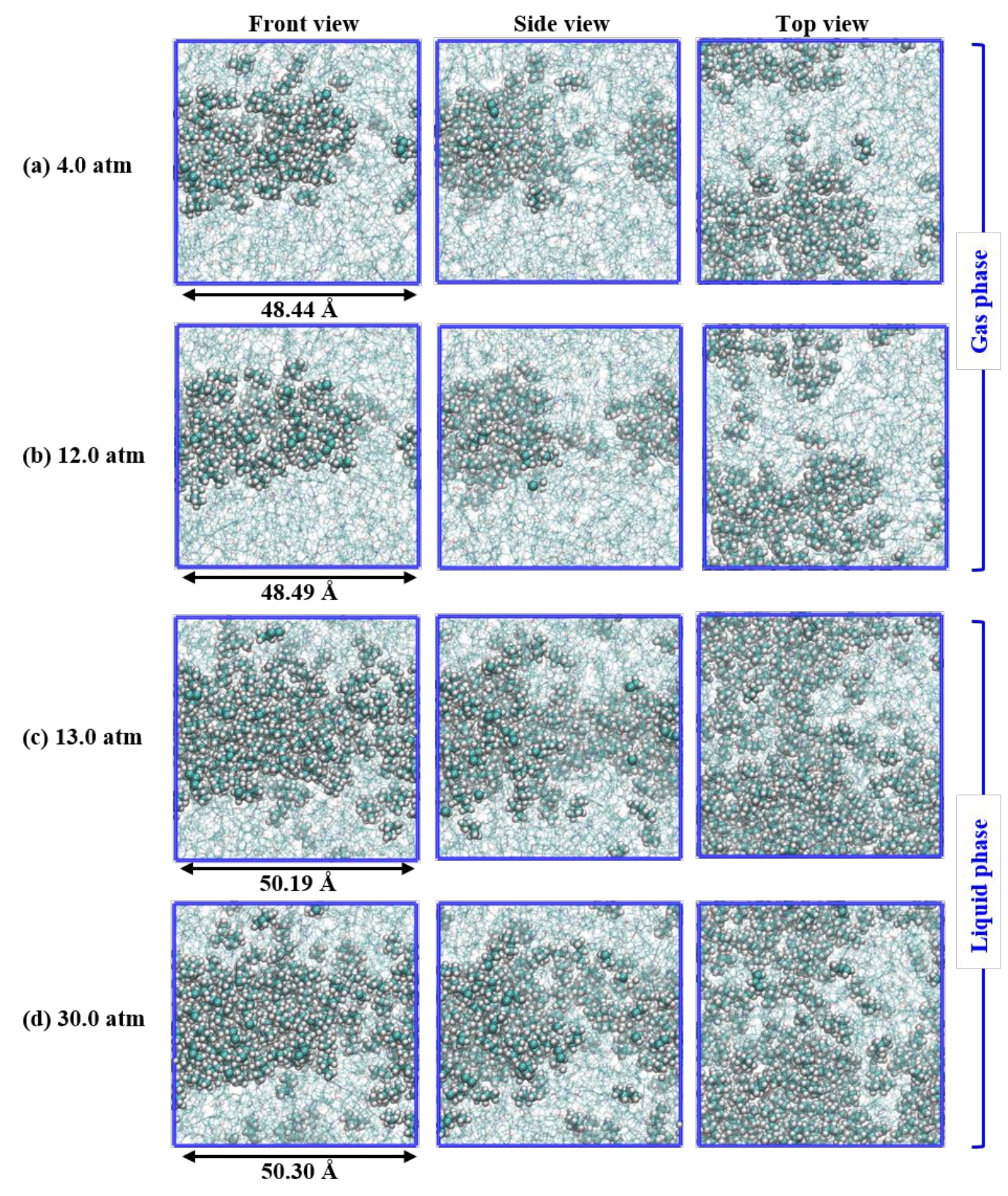

Figure S14. Front, side and top view of the flexible kerogen matrix with $n-\mathrm{C}_{4} \mathrm{H}_{10}$ sorption at different pressures: $T=363.15 \mathrm{~K}$. 
(a) $2.0 \mathrm{~atm}$

(b) $4.0 \mathrm{~atm}$
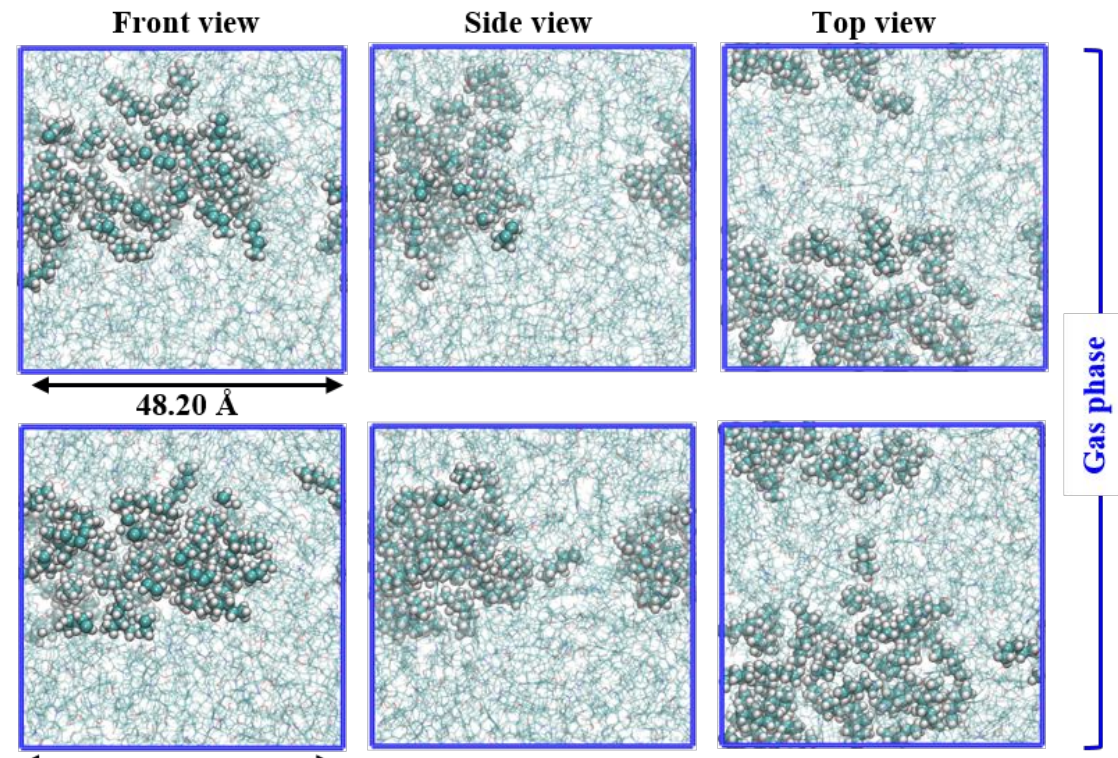

(c) $5.0 \mathrm{~atm}$
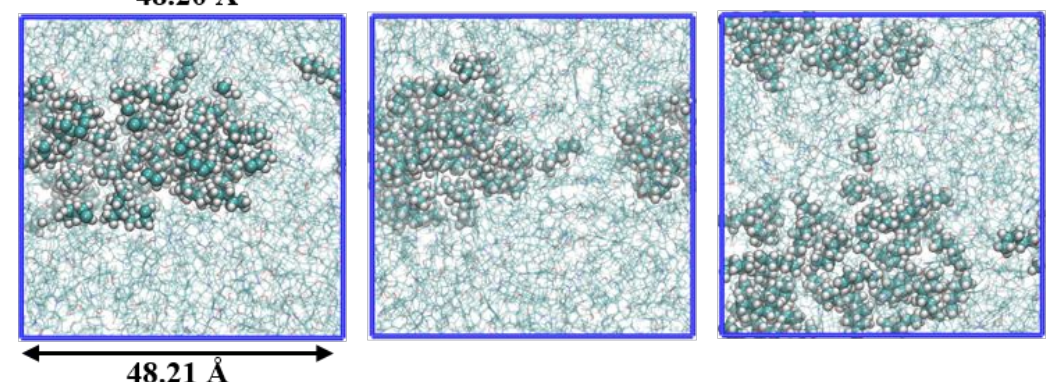

है

(d) $20.0 \mathrm{~atm}$
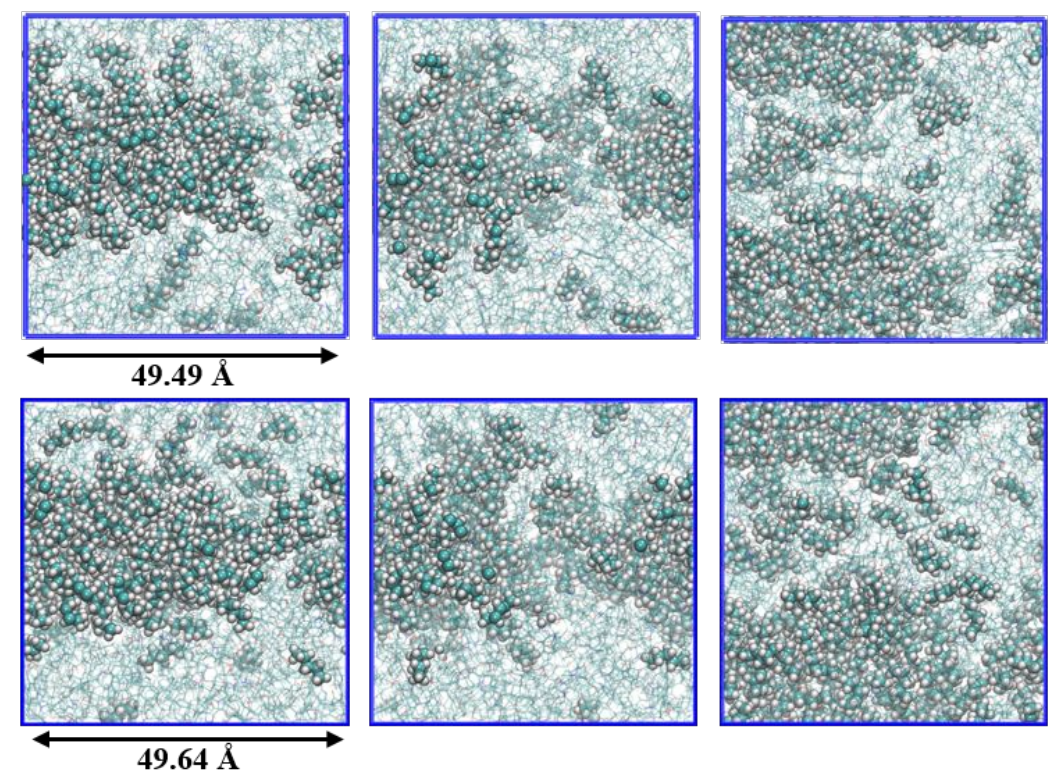

」气

Figure S15. Front, side and top view of the flexible kerogen matrix with $n-\mathrm{C}_{5} \mathrm{H}_{12}$ sorption at different pressures: $T=363.15 \mathrm{~K}$. 


\section{Reference}

(1) $\mathrm{Wu}, \mathrm{T}$.; Firoozabadi, A. Effect of Microstructural Flexibility on Methane Flow in Kerogen Matrix by Molecular Dynamics Simulations. J. Phys. Chem. C 2019, 123, 1087410880.

(2) Tesson, S.; Firoozabadi, A. Deformation and Swelling of Kerogen Matrix in Light Hydrocarbons and Carbon Dioxide. J. Phys. Chem. C 2019, 123, 29173-29183.

(3) National Institute of Standards and Technology. Thermophysical Properties of Fluid Systems. https://webbook.nist.gov/chemistry/fluid/ (accessed August 2, 2020). 